УДК: 004.832.25; 519.862.5

JEL Classification: C 02

М. С. СІНИЦБКИЙ,

кандидат фізико-математичних наук,

дочент кафедри інформачійних технологій,

Національна академія статистики, обліку та аудиту

\title{
До питання розв'язку обернених задач економічного спрямування
}

В статті проаналізовано різнобічні варіанти побудови систем підтримки прийняття рішень при плануванні фінансово-виробничої діяльності підприємств на основі розв'язку обернених задач. Розглянуто їх недоліки та вказано на проблематику існуючих на сьогодні пропозицій. Показано, щуо для знаходження обернених рішень необхідно використовувати оптимізаційні методи на всіх рівнях декомпозиції иілей.

Ключові слова: системи підтримки прийняття рішень, обернені розв'язки, MS Excel, детермінований факторний аналіз, виробничі функиіі.

Постановка проблеми. При прийнятті рішень щодо подальшої фінансововиробничої діяльності підприємства як правило використовують певні узагальнюючі показники, отримані за допомогою фінансового аналізу результатів попередніх звітних періодів. Управлінська дія передбачає знаходження відповіді на питання “як зробити так, щоб..?”. 3 позицій фінансово-економічного моделювання це означає, що потрібно розв'язати задачу, зворотну прямій задачі, яка відповідає на питання “як $€$ ?”. Наприклад, якщо визначення прибутку на основі даних щодо виручки і собівартості продукції є прямою задачею, то відповідь на питання, якими мають бути обсяги продажів та/або відпускні ціни для отримання заданого прибутку, є розв'язком оберненої задачі.

Так само можна поставити обернену задачу щодо похибок, а саме: якими мають бути первинні показники, щоб була забезпечена задана похибка узагальнюючого показника.

Аналіз останніх досліджень і публікацій. У пострадянській літературі застосування обернених рішень в управлінні підприємством започатковано роботами В. Діка [1] та Б. Одинцова [2]. В [1] показано, що підсистема діагностики фінансового стану підприємства систем підтримки прийняття рішень (СППР) у найпростішому варіанті реалізації має спиратися на методи детермінованого факторного аналізу фінансових показників [3], побудованих на порівнянні їх планових і фактичних значень. Детермінований факторний аналіз виявляє ті показники, що мали найбільший вплив на відхилення результатних показників від їх нормативних значень. Таким чином на основі певних правил формується діагноз ситуації. Щоправда, оскільки розмірності реальних задач великі, то йдеться ще й про вибір із безлічі діагнозів найоптимальнішого, що так чи інакше вимагає зниження розмірності, як правило, шляхом класифікації, побудованої на ієрархічній підпорядкованості (дереві рішень).

В. В. Дік розглянув варіант процедури обернених рішень [1, с. 130] і показав, що застосовуючи принцип логічного програмування, тобто ідучи за деревом декомпозиції цілей зверху вниз і зліва направо, можна однозначно виявити ресурси, потрібні для виконання прийнятого рішення. При цьому кожна термінальна вершина дерева цілей характеризується обмеженнями на відповідний ресурс (в умовному розумінні ${ }^{1}$ ). Щоправда, визначення цих обмежень виходить за рамки можливостей запропонованої СППР.

Додатковим предметом аналізу є виявлення знаків і темпів зміни факторів. Останнє дозволяє позначити вершини графу знаками “плюс" або “мінус" в залежності від бажаного напрямку зміни відповідного показника, а при збігу напрямків зміни на кожному кроці $K$-ситуаційного аналізу віддавати перевагу найпотужнішому з них.

\footnotetext{
${ }^{1}$ До ресурсу в цій трактовці належить, наприклад, ціна. Див. далі.
}

(c) М. Є. Сіницький, 2018 
Для задачі збільшення прибутку (показник $A$ ) за рахунок підвищення виручки $(B)$ і зменшення собівартості реалізованої продукції $(C)$ схема аналізу виглядає, як показано на рис. 1. Другий рівень рішень представлено гілками, що визначають шляхи підвищення виручки $(B)$ за рахунок збільшення числа продаж $(D)$, зниження ціни $(E)$ і збереження залишку від виручки на попередньому рівні $(F)$, а також зменшення

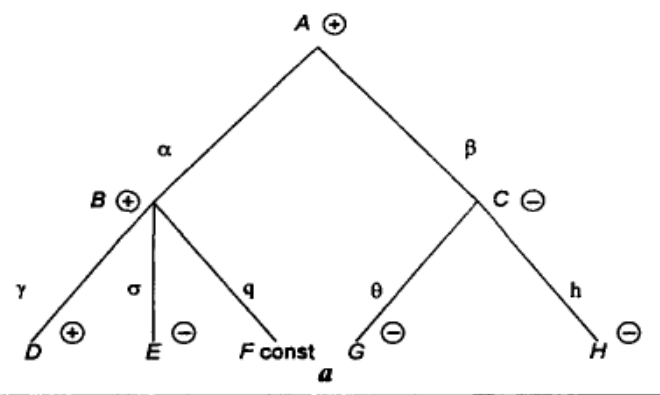

\begin{tabular}{|c|c|c|c|c|c|c|c|c|}
\hline & $A$ & $B$ & $C$ & $D$ & $E$ & $F$ & $G$ & $H$ \\
\hline$A$ & $\oplus$ & $\alpha$ & $\beta$ & & & & & \\
\hline$B$ & & $\oplus$ & & $\gamma$ & $\sigma$ & $q$ & & \\
\hline$C$ & & & $\Theta$ & & & & $\theta$ & $\mathrm{h}$ \\
\hline$D$ & & & & $\oplus$ & & & & \\
\hline$E$ & & & & & $\Theta$ & & & \\
\hline$F$ & & & & & & const & & \\
\hline$G$ & & & & & & & $\Theta$ & \\
\hline$H$ & & & & & & & & $\Theta$ \\
\hline
\end{tabular}

Рис. 1. Дерево цілей (а) і матриця суміжності графа рішень (б) задачі декомпозиції комплексного показника

Джерело: [1]

собівартості продукції $(C)$ за рахунок зниження прямих виробничих $(G)$ і накладних $(H)$ витрат. Грецькі літери позначають ваги гілок, які відповідають коефіцієнтам пріоритетності цілей (КПЦ), що визначаються особою, яка приймає рішення. Важливо, що для кожного розгалуження за теорією методу аналізу ієрархій Т. Сааті [4] сума ваг має дорівнювати одиниці, тобто

$$
\alpha+\beta=1 ; \gamma+\sigma+q=1 ; \theta+h=1 .
$$

Математично задача досягнення цілі, тобто збільшення показника А на величину $\triangle A$, може бути представлена системою рівнянь:

$$
\left\{\begin{array}{c}
\Delta A(B)+\Delta A(C)=\Delta A ; \\
\Delta A(B)=f_{1}(\alpha, B) ; \\
\Delta A(C)=f_{2}(\beta, C),
\end{array}\right.
$$

де $\triangle A(B)$ - приріст $A$ за рахунок збільшення показника $B$;

$\triangle A(C)$ - приріст $A$ за рахунок збільшення показника $C$;

$f_{1}(\alpha, \mathrm{B}), f_{2}(\alpha, \mathrm{B})$ - обернені функції, що відображують засоби, потрібні для досягнення цілі.

Б. Ф. Одинцов [5] розширив цей підхід, запропонувавши метод розв'язку обернених задач, названий ним оберненими обчисленнями. Специфіка методу полягає в тому, що обчислення не вимагають знання оберненої функції. Нескладними розрахунками (розв'язком квадратного рівняння) знаходять координати окремих точок у діапазоні можливих змін аргументів функції, що їх пов'язує. Коректність задачі обгрунтовується, на думку автора, іiі довизначенням за допомогою накладання обмежень на відношення розв'язків щодо шуканих приростів змінних у вигляді відношення коефіцієнтів відносної важливості аргументів, тобто КПЦ:

$$
\Delta B / \Delta C=\alpha / \beta,
$$


Ці відношення задає особа, яка приймає рішення, і про те, як вона їх обгрунтовує, автор [5] не пояснює. Тобто запропонований у [5] варіант розв'язку оберненої задачі є лише інструментом перетворення відношення коефіцієнтів відносної важливості аргументів у прирости цих аргументів. Крім того, очевидним недоліком цього підходу $€$ неможливість нульового приросту показника $C$.

Описаний метод, завдяки його простоті, був запозичений освітянами як рішення для СППР, хоча до реальних систем справа поки що не дійшла. Згодом автори [6] уточнили, що в якості обмежень (3) варто брати відношення факторних навантажень приросту інтегрального показника $\Delta A$. В тій самій роботі запропоновано ітераційний метод покращення цільової функції та перерозподілу внутрішніх ресурсів у разі їх нестачі для досягнення цілі.

У роботах автора $[7 ; 8]$ задача обернених обчислень розглянута як задача нелінійного програмування з квадратичною цільовою функцією, яка в термінах формули (2) має вигляд:

$$
(\Delta B)^{2}+(\Delta C)^{2} \rightarrow \min .
$$

Було зроблено висновок, що без накладання обмежень виду (3), як це слідує з методики [4], оптимізація з ціллю (4) дає мінімальні значення шуканих величин $\Delta B$ і $\Delta C$.

Мета дослідження. Проаналізувати способи розв'язку обернених задач менеджменту підприємств та запропонування на його основі рекомендації щодо покращення планування фінансово-виробничої діяльності.

Результати дослідження. Розглянемо елементарну модель мультиплікативного типу з двома факторами, яка використовується при описі декомпозиції цілі вищого рівня на дві цілі нижчого рівня.

Типовий приклад оберненої задачі в такій постановці: визначення приростів ціни $\left(\Delta p=p_{1}-p_{0}\right)$ й кількості проданого штучного товару $\left(\Delta q=q_{1}-q_{0}\right)$ для забезпечення заданого значення виручки $\left(r_{1}\right)$ :

$$
r_{1}=r_{0}+\Delta r=p_{1} * q_{1}=\left(p_{0}+\Delta p\right) *\left(q_{0}+\Delta q\right),
$$

якщо відомі $p_{0}$ i $q_{0}$ на початку періоду.

Нехай $p_{0}=10,00$ грн/шт.; $q_{0}=5,00$ шт.; $r_{1}=100,00$ грн [7]. Без накладання додаткових обмежень задача матиме дискретну множину рішень, оскільки $q$ ціле. Користуючись підходом [5], уведемо, як у [7], обмеження типу (3), що представляє волю особи, яка приймає рішення:

$$
\frac{p_{1}-p_{0}}{q_{1}-q_{0}}=\frac{\Delta p}{\Delta q}=\frac{\alpha}{\beta}=\frac{0,75}{0,25}=3 \frac{\text { грн. }}{\mathrm{um}^{2}} .
$$

Діючи за [5], розв'язок оберненої задачі отримують з системи рівнянь:

$$
\left\{\begin{array}{c}
r_{0}+\Delta r=\left(p_{0}+\Delta p\right) *\left(q_{0}+\Delta q\right) \\
\frac{\Delta p}{\Delta q}=\frac{\alpha}{\beta}
\end{array} .\right.
$$

що приводить до розв'язку квадратичного рівняння:

$$
\frac{\alpha}{\beta} *(\Delta q)^{2}+\left(p_{0}+\frac{\alpha}{\beta} * q_{0}\right) * \Delta q+p_{0} * q_{0}-\left(r_{0}+\Delta r\right)=0
$$

Беручи корінь, що відповідає значенню $r_{l}$, матимемо: $\Delta p=5,00$ грн/шт.; $\Delta q=1,67$ шт., тобто $p_{1}=15,00$ грн/шт., $q_{1}=6,67$ шт., $r_{1}=15,00 * 6,67=100,05$ грн.

Оскільки в нашій постановці аргумент $q$ має бути цілим числом, даний варіант розв'язку через (7) не $є$ задовільним. Крім того, згідно з [4] $\alpha$ і $\beta$ мають бути безрозмірними коефіцієнтами, а у (6)-(8) $\alpha / \beta$ має розмірність грн/шт. ${ }^{2}$.

Спробуємо розв'язати задачу обернених обчислень методами математичного програмування, які містить процесор електронних таблиць (ET) MS Excel. В якості обмежень використаємо умову цілочисельності величини $\Delta q$ і умову $\Delta p \geq 0$. Крім того, оскільки в роботі [6] ліву частину другого рівняння системи (7) змінено на відношення 
факторних навантажень $\Delta r_{\mathrm{p}} / \Delta \mathrm{r}_{\mathrm{q}}$, підраховане за інтегральним методом детермінованого факторного аналізу [3], тобто:

$$
\frac{\Delta r_{p}}{\Delta r_{q}}=\frac{0,5^{*} \Delta p^{*}\left(q_{0}+q_{1}\right)}{0,5^{*} \Delta q^{*}\left(p_{0}+p_{1}\right)}=\frac{\Delta p^{*}\left(2 q_{0}+\Delta q\right)}{\Delta q^{*}\left(2 p_{0}+\Delta p\right)}=\frac{\alpha}{\beta},
$$

то для перевірки цього варіанту у розрахунки додамо знаходження факторних навантажень та їх відношень, а також розрахунок величини $\Delta p * \Delta q$, яка $€$ неподільним залишком факторного розкладання величини $\Delta r$.

На рис. 2 представлено копію екрану ЕТ з результатами виконання

\begin{tabular}{|c|c|c|c|c|c|c|}
\hline \multicolumn{2}{|r|}{ E9 } & -8 & \multicolumn{2}{|c|}{$f_{x}=(\mathrm{A} 11+\mathrm{C} 2)^{*}(\mathrm{~A} 13+\mathrm{D} 2$} & \multirow[b]{2}{*}{$E$} & \multirow[b]{2}{*}{$F$} \\
\hline 4 & A & B & $\mathrm{C}$ & D & & \\
\hline 1 & & & $\Delta p$ & $\Delta \mathrm{q}$ & $\Delta p / \Delta q$ & $\Delta p * \Delta q$ \\
\hline 2 & & Розв'язок & 4,99999855 & 1,64999966 & 3,030302774 & 8,24999593 \\
\hline 3 & & $3 a[6-7]$ & 5 & \begin{tabular}{|r|}
1,65 \\
\end{tabular} & 3,03030303 & 8,25 \\
\hline 4 & & & $\Delta r_{p}$ & $\Delta r_{q}$ & $\Delta \mathrm{r}$ & \\
\hline 5 & & Навантаження & 29,125 & 20,6249988 & 49,74999881 & \\
\hline 6 & & $\Delta r_{p} / \Delta r_{q}=$ & 1,41212129 & 1,41212113 & & \\
\hline 7 & & $\Delta r_{p} /\left(\Delta r_{p}+\Delta r_{q}\right)=$ & 0,58542715 & 0,41457285 & & ціль \\
\hline 8 & $r_{0}$ & $r_{1}$ & $r_{1}$ & & Обмеження & $\mathrm{F}=(\Delta \mathrm{p})^{\wedge} 2+(\Delta \mathrm{q})^{\wedge} 2$ \\
\hline 9 & 50 & 99,75 & 99,7499853 & & 99,74998533 & 27,7224844 \\
\hline 10 & $p_{0}$ & $p_{1}$ & $p_{1}$ & $\Delta r_{q}=$ & 20,62499459 & \\
\hline 11 & 10 & 15 & 14,9999986 & $\Delta r_{p}=$ & 29,12499074 & \\
\hline 12 & $q_{0}$ & $q_{1}$ & $\mathrm{q}_{1}$ & & $\Delta p>=0$ & \\
\hline 13 & 5 & 6,65 & 6,64999966 & & $\Delta q=$ ціле & \\
\hline 14 & & & $\Delta r_{p} / \Delta r_{q}=$ & 1,41212129 & 1,412121133 & \\
\hline 15 & & & $\Delta p / \Delta q=$ & 3,03030303 & 3,030302774 & \\
\hline
\end{tabular}

\section{Рис. 2. Розв'язок оберненої задачі методом нелінійного програмування}

Комірки, що відображують дані авторів [6; 7], позначено сірим кольором. Комірки цілі та обмежень виділено жирними рамками.

Джерело: розраховано автором

процедури «Пошук розв'язку» для вище описаної постановки задачі з мінімізацію квадратичної функції виду (4). Як і очікувалось, програма не знайшла розв'язку, а саме: не вдалось одночасно виконати обмеження $\Delta p / \Delta q=3$ (комірка $E 2)$ і $\Delta q=ц і л е(D 2)$, хоча всі інші умови дотримано і результати збігаються.

Звернемо увагу також на те, що використання в якості обмеження відношення факторних навантажень $\Delta r_{\mathrm{p}} / \Delta \mathrm{r}$, яке за [6] визначається на першій ітерації за розв'язком системи (7), нічого не змінило б, оскільки, як бачимо з рис. 2, ця умова також виконується (значення комірок C6 і D6 збігаються).

В разі, коли обмеження $\Delta p / \Delta q$ не використовується, програма знаходить цілочисельний розв'язок для $\Delta q$ (комірка $D 2)$ (рис. 3). При цьому

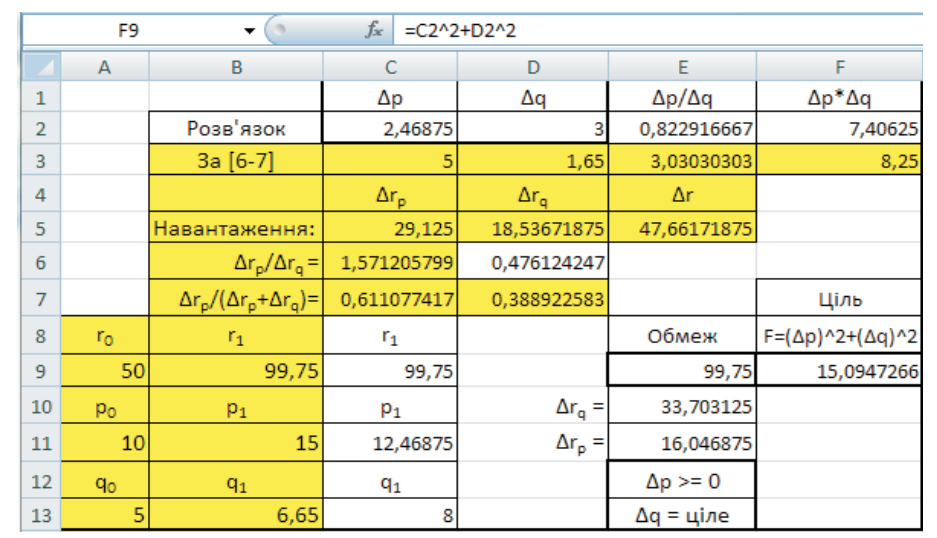

Рис. 3. Розв'язок оберненої задачі методом нелінійного програмування без використання обмеження на відношення $\Delta p / \Delta q$

Джерело: розраховано автором 
досягнуте значення цільової функції $\mathrm{F}(F 9)$ майже удвічі менше, ніж у попередньому варіанті. Крім того, на 10\% зменшився неподільний залишок факторного розкладання $(F 2)$, що разом свідчить про оптимальніший результат.

Виникає питання, чи можна побудувати процедуру розв'язку розглянутої оберненої задачі на мінімізації неподільного залишку факторного аналізу $\Delta p * \Delta q$ ? На рис. 4 представлено копію екрану ЕТ з відповідними результатами. Програма знаходить розв'язок, що задовольняє всім обмеженням, при майже вдвічі меншому значенні добутку $\Delta p * \Delta q$ в порівнянні $з$ попередніми варіантами (4,33 грн проти 8,25 грн).

\begin{tabular}{|c|c|c|c|c|c|c|}
\hline \multicolumn{3}{|c|}{ F9 } & $f_{x}$ & \multicolumn{3}{|l|}{$=\mathrm{C} 22^{*} \mathrm{D} 2$} \\
\hline 4 & A & B & C & D & E & $\mathrm{F}$ \\
\hline 1 & & & $\Delta p$ & $\Delta \mathrm{q}$ & $\Delta p / \Delta q$ & $\Delta p^{*} \Delta q$ \\
\hline 2 & & Розв'язок & 1,083333444 & 4 & 0,270833361 & 4,333333778 \\
\hline 3 & & $3 a[6-7]$ & 5 & 1,65 & 3,03030303 & 8,25 \\
\hline 4 & & & $\Delta r_{p}$ & $\Delta r_{q}$ & $\Delta r$ & \\
\hline 5 & & Навантаж & 29,125 & 17,3937501 & 46,51875009 & \\
\hline 6 & & $\Delta r_{p} / \Delta r_{q}=$ & 1,674452021 & 0,17984191 & & \\
\hline 7 & $\Delta r_{p} /$ & $\left(\Delta r_{p}+\Delta r_{q}\right)=$ & 0,626091628 & 0,37390837 & & ціль \\
\hline 8 & $r_{0}$ & $r_{1}$ & $r_{1}$ & & обмеження & $F=\Delta p^{*} \Delta q$ \\
\hline 9 & 50 & 99,75 & 99,750001 & & 99,750001 & 4,333333778 \\
\hline 10 & $p_{0}$ & $\mathrm{p}_{1}$ & $\mathrm{p}_{1}$ & $\Delta r_{q}=$ & 42,16666689 & \\
\hline 11 & 10 & 15 & 11,08333344 & $\Delta r_{p}=$ & 7,583334111 & \\
\hline 12 & 90 & $q_{1}$ & $\mathrm{q}_{1}$ & & $\Delta p>=0$ & \\
\hline 13 & 5 & 6,65 & 9 & & $\Delta q=$ ціле & \\
\hline
\end{tabular}

\section{Рис. 4. Розв'язок оберненої задачі методом лінійного програмування}

Джерело: розраховано автором

Зрозуміло, що з точки зору квадратичної функції цілі цей розв'язок менш оптимальний, бо в цьому варіанті величина $(\Delta p)^{2}+(\Delta q)^{2}$ дорівнює 17,1736, що більше, ніж у попередньому варіанті: 15,0945.

Ще одне питання, яке вимагало уточнення, - чи не покращаться результати, якщо оперувати з даними в індексному уявленні? Для отримання відповіді аналогічні попереднім процедури оптимізації застосовувались до вхідних величин, нормованих на їх базові значення.

Порівняння отриманих результатів 3 попередніми представлено на рис. 5. Бачимо, що використання індексів суттєво впливає на результати. За натуральних одиниць

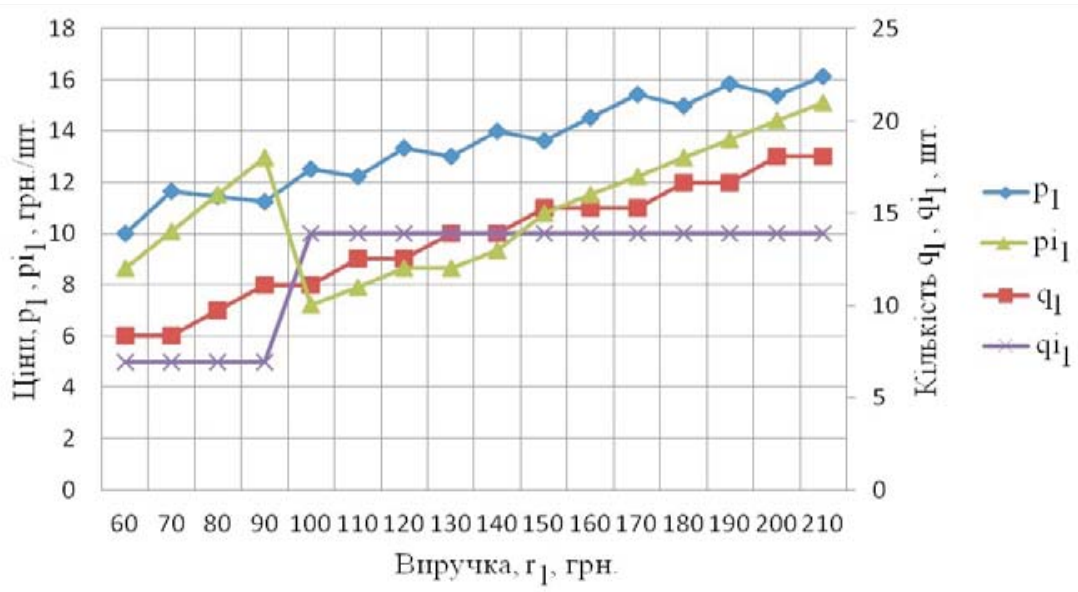

Рис. 5. Порівняння залежностей цін і кількостей продажів, що забезпечують заплановану виручку при різних поданнях вхідних даних

$p_{1} \mathrm{i} q_{1}$ - натуральні одиниці; $p i_{1}$ i $q i_{1}-$ в індексному вираженні.

Джерело: розраховано автором 
вимірювання змінних графіки обернених розв'язків мають рівномірно-ступінчастий характер з одиничним кроком за кількістю, а при використанні індексів крок ступенів дорівнює $q_{0}$. Це пояснюється дотриманням вимоги цілочисельності $\Delta q$.

Який з варіантів кращий? Для необмежених ресурсів можна опиратися на рис. 5, але в реальній економіці так не буває. 3 одного боку, ринок диктує свої умови щодо екзогенних факторів, і їх слід враховувати. Наприклад, якщо не йдеться про монополію, ціною продукції навряд чи можна маніпулювати в широких межах. Так само не можна впливати на вартість ресурсів (комплектуючих і матеріалів, робочої сили тощо). 3 іншого боку, рішення підприємства щодо виробництва певного обсягу і номенклатури продукції, а також попиту на фактори виробництва залежить від використовуваної ним технології, яка в результаті визначає обмеження на ендогенні фактори виробництва: капітал і працю.

Автори робіт $[1 ; 2 ; 5 ; 6]$ для застосування обернених обчислень на всіх рівнях схеми прийняття рішень, представленої на рис. 1, розширили, на їхню думку, розуміння взаємозамінності ресурсів, додавши до них ціни, витрати, собівартість, банківський відсоток тощо. На нашу думку, це тільки гра термінологій, тому що, як відомо, 3 позиції максимізації прибутку максимально можливий рівень випуску продукції для даної кількості виробничих ресурсів на даному рівні технології описують виробничі функції (ВФ) (див., напр., [9; 10]).

Щоправда, вибір ВФ, адекватної економічним реаліям, які вона моделює, залежить від багатьох вимог. Це й належність до класу неокласичних функцій, степінь однорідності (віддача від масштабу), еластичність заміщення між факторами та інші. Детальний аналіз можна знайти у [11].

Використання ВФ підприємства чи галузі в оптимізаційній процедурі на рівні ресурсного планування забезпечуватиме збереження максимуму прибутку, що є головною метою виробничої діяльності.

Комбінація декількох критеріїв приводить до багатокритеріальних оптимізаційних задач - проблема, якою кібернетики займаються вже більше півстоліття. Саме в цьому напрямку доцільно розвивати й розглянутий вище підхід до побудови СППР.

\section{Висновки}

1. Методи обернених обчислень, запропоновані в $[1 ; 2 ; 5 ; 6]$ для побудови СППР 3 планування виробничої діяльності, $є$ частинними і неоптимальними.

2. Для розв'язання елементарних обернених задач придатні методи квадратичного математичного програмування з цілочисельними обмеженнями, побудовані на добре регуляризованих процедурах оптимізації, що включені до пакету MS Excel.

3. Перспективною основою для побудови СППР з планування виробничої діяльності підприємств з використанням обернених обчислень $є$ застосування на рівні визначення ресурсів інструментарію виробничих функцій, які забезпечують максимізацію прибутку діяльності.

\section{Список використаних джерел}

1. Дик В. В. Методология формирования решений в экономических системах и инструментальные среды их поддержки. М.: Финансы и статистика, 2000. 300 с.

2. Романов А. Н., Одинцов Б. Ф. Советующие информационные системы в экономике. М.: ЮНИТИ, 2000. 487 с.

3. Баканов М. И., Шеремет А. Д. Теория экономического анализа: учебник. М.: Финансы и статистика, 1998.416 с.

4. Саати Т. Принятие решений. Метод анализа иерархий. Пер. с англ. Р. Г. Вачнадзе. М.: Радио и связь, 1993. 278 с.

5. Одинцов Б. Ф. Обратные вычисления в формировании экономических решений: учеб. пособ. М.: Финансы и статистика, 2004. 192 с.

6. Одинцов Б. Ф., Романов А. Н. Итерационный метод оптимизации управления предприятиями средствами обратных вычислений // Вестник финансового университета. 2014. № 2. С. 60-73.

7. Грибанова Е.Б. Методы решение обратных задач экономического анализа // Корпоративные финансы. 2015. Вып. 4(36). С. 119-128. 
8. Грибанова Е. Б. Решение обратных задач экономики с помощью модифицированного метода обратных вычислений // Проблемы управления. 2016. № 5. С. 35-40.

9. Черемных Ю. Н. Микроэкономика. Продвинутый уровень: учебник. М.: ИНФРА-М, 2008. $844 \mathrm{c}$.

10. Мицель А. А. Математическое и имитационное моделирование экономических процессов. Томск: Изд-во ТУСУР, 2016. 193 с.

11. Казакова М. В. Анализ свойств производственных функций, используемых при декомпозиции экономического роста. М.: Препринт WP Российской академии народного хозяйства и Государственной службы при президенте Российской федерации, 2013. 48 с.

\section{References}

1. Dik V. V. (2000). Metodologiya formirovaniya resheniy v ekonomicheskih sistemah i instrumentalnyie sredyi ih podderzhki [Methodology of decision making in economic systems and instrumental environments for their support]. Finansyi i statistika-Finance and statistics [in Russian].

2. Romanov A. N., Odintsov B. F. (2000). Sovetuyuschie informatsionnyie sistemyi v ekonomike [Advisory information systems in economics]. M.: YuNITI [in Russian].

3. Bakanov M. I., Sheremet A. D. (1998). Teoriya ekonomicheskogo analiza [Theory of economic analysis]. M.: Finansyi i statistika [in Russian].

4. Saati T. (1993). Prinyatie resheniy. Metod analiza ierarhiy [Method for the analysis of hierarchies]. Translated from English by R. G. Vachnadze. M.: Radio i svyaz [in Russian].

5. Odintsov B. F. (2004). Obratnyie vyichisleniya v formirovanii ekonomicheskih resheniy [Inverse calculations in making economic decisions]. M.: Finansyi i statistika [in Russian].

6. Odintsov B. F., Romanov A. N. (2014). Iteratsionnyiy metod optimizatsii upravleniya predpriyatiyami sredstvami obratnyih vichisleniy [Iteration method for optimization of company management by methods of inverse calculations]. Vestnik finansovogo universiteta - Bulletin of Financial University, 2, 60-73 [in Russian].

7. Gribanova E. B. (2015). Metodyi reshenie obratnyih zadach ekonomicheskogo analiza [Methods for solving inverse problems in economic analysis]. Korporativnyie finansyiCorporate finance, 4(36), 119-128 [in Russian].

8. Gribanova E. B. (2016). Reshenie obratnyih zadach ekonomiki s pomoschyu modifitsirovannogo metoda obratnyih vyichisleniy [Solving inverse problems in economics using the modified method for inverse calculations]. Problemyi upravleniya-Problems of management, 5, 35-40 [in Russian].

9. Cheremnyih Yu. N. (2008). Mikroekonomika. Prodvinutyiy uroven [Microeconomics. The advanced level]. M.: INFRA-M [in Russian].

10. Mitsel A. A. (2016). Matematicheskoe i imitatsionnoe modelirovanie ekonomicheskih protsessov [Mathematical and imitation modeling of economic processes]. Tomsk: Izdvo TUSUR [in Russian].

11. Kazakova M. V. (2013). Analiz svoystv proizvodstvennyih funktsiy, ispolzuemyih pri dekompozitsii ekonomicheskogo rosta [The analysis of properties of production functions: use for decomposition of economic growth]. M.: Preprint WP Rossiyskoy akademii narodnogo hozyaystva i Gosudarstvennoy sluzhbyi pri prezidente Rossiyskoy federatsii [Preprint WP of the Russian Academy of Economic Management and the State Service at the President of the Russian Federation] [in Russian]. 
Н. Е.СИНИЦКИЙ,

кандидат физико-математических наук, дочент кафедры информационных технологий, Национальная академия статистики, учета и аудита

\title{
К вопросу решения обратных задач экономического направления
}

В статье рассмотрены некоторые подходы к построению систем поддержки принятия решений по планированию финансово-производственной деятельности предприятия на основе обратных вычислений. На численных примерах продемонстрированы недостатки и проблематика существующих предложений. Показано, что обратные решения должсны находиться оптимизационными методами на всех уровнях декомпозииии целей.

Ключевые слова: системы поддержки принятия решений, обратные решения, MS Excel, детерминированный факторньй анализ, производственные функции.

\author{
M. E. SINYTSKYI, \\ PhD (Phys. \& Math.), \\ Associate Professor of Information Systems and Technology Department, \\ National Academy of Statistics, Accounting and Audit
}

\section{To the Solution of Inverse Problems of an Economic Nature}

Planning of the current production and financial activities of the enterprise is carried out based on financial statements for previous periods.

It has been proposed by a number of authors to build decision support systems for managers grounding on the solutions of inverse problems of factor analysis of generalized indicators used at different levels of goal decomposition. In these works, the required parameters are found by solving quadratic equations with subsequent selection of verified radicals; the equations are obtained via the additional definition of the factor systems by the ratio of the coefficients of the relative importance of arguments. The coefficients are set by the decision maker.

The article demonstrates such solution to be a special case that is not suitable for piece production and is not optimal from the standpoint of minimizing the costs of resources and maximizing profits. Moreover, given solution represents only a transformation of the coefficients of the relative importance of arguments into increments of these arguments.

The quantitative analysis carried out in the article allows us to conclude that the methods of non-linear optimization of production functions should be applied at all levels of decomposition of the enterprise's goal when it comes to redistribution of resources.

Keywords: decision support systems, inverse solutions, MS Excel, determinestic factor analysis, production functions.

\section{Посилання на статтю:}

Сіницький М. Є. До питання розв'язку обернених задач економічного спрямування // Науковий вісник Національної академії статистики, обліку та аудиту: зб. наук. пр. 2018. №1-2. С. 195-202. 